\title{
Chapter 14 \\ THE RELATIONSHIP BETWEEN WAVE ACTION AND BEACH PROFILE CHARACTERISTICS
}

\author{
P. H. Kemp \\ Depertment of Civil Engineering. \\ University College London, England.
}

\section{ABSTRACT.}

The rational design of coast protection works requires a knowledge of the behaviour of the beach under natural conditions. The understanding of the relationship between the waves acting on the beach and the characteristics of the beach profile produced, is thus a necessary preliminary to the analysis of the causes of beach erosion and the evaluation of the effect of projected remedial measures.

The present paper describes the results of a series of preliminary hydraulic model experiments carried out by the author prior to a model study of the behaviour of groymes in stabilising beaches. Most of the beach materials used represented coarse sand or shingle in nature.

The results demonstrate the fundamental importance of the "phasedifference" in terms of wave period between the break-point and the limit of uprush, in relation to flow conditions, cusp formation, and the change from "step" to "bar" type profiles.

Within the limits of the experiments an expression connecting the breaker height, beach profile length, and grain diameter is developed, and its implications examined in relation to beach slope, and to the previous "wave steepness" criterion for the change from step to bar type profiles.

Observations are included on the rate of recession of a shoreline due to the onset of more severe wave conditions.

\section{INTRODUCTION.}

BEACF CHANGES.

Chenges in the coastline may be classified as:-

(1) Progressive changes resulting in prograding or recession of the shoreline over a long period of time.

(2) Short term variations which reflect the fluctuating nature of the forces acting on the beach.

An examination of both these aspects would require a study of the forces acting, the type, quantity, source and behaviour of the beach material, the submarine contours, and the regional geology. 


\section{THE RELATIONSHIP BETWEEN WAVE ACTION AND BEACH PROFILE CHARACTERISTICS}

This paper relates to the mechanics of the short term variations in beach profile characteristics.

It is reasonable to suppose that if waves of given characteristics act on a beach composed of particles which are capable of being moved under the action of the wave forces, then the beach will take up a configuration or profile characteristic of the waves and of the beach materiel. This relationship was remarked upon by Cornish (1) who defined the final beach configuration due to a given set of wave conditions as the "equilibrium profile" or regimen of the beach. Fenneman (2) defined such a profile as "that which the water would impart if allowed to cerry its work to completion". This equilibrium form is probably seldom attained in nature.

Whereas the hydraulic model is a valuable aid to the understanding of beach processes, the variability of wave conditions in nature, together with the lack of complete reaction by the beach, makes the problem of correlating model and prototype measurements correspondingly difficult.

BEACH STUDIES.

So far no generalised theory has resulted from the many observations which have been made both in the laboratory and in the field.

Beach profiles have however been broadly classified as one or other of two types. These types are generally associated with steep waves and with low waves. The two beach profile types have been variously defined as

(a) sumer, ordinary, or berm type

(b) winter, storm, or bar type.

Typical profiles are stown in Figure 1. One pasic difference between these profiles when well developed is the presence of a "step" in case (a), and a "bar" in case (b). Type (a) is frequently found on shingle beaches, and type (b) on sand beaches. The profiles will be referred to as step type and bar type.

Waters(3) carried out a series of experiments on beach profiles and concluded that the change from step to bar type profiles was a function of deep water wave steepness $\mathrm{H}_{\mathrm{O}} / \mathrm{I}_{\mathrm{O}}$. He found the critical value to lie between 0.02 and 0.03 , the bar type existing for the higher values. Similar reaults have been found by other investigators. Field studies by Patrick and Wiegel (4) have not confirmed these model values of critical wave steepness, and much lower values have been quoted $(5),(6)$.

Bagnold (7) has show that for step type beaches, the beach crest height is proportional to the wave height. Experiments have also 


\section{COASTAL ENGINEERING}

shown that profiles produced during variations in tidal range and wave period do not differ appreciably from the profiles formed under constant conditions (8), (9).

\section{PRESENT EXPERIMEITSS.}

APPARATUS.

The wave tank was a small three dimensional model with oversil dimensions $15^{\prime} 0^{\prime \prime} \times 9^{\prime \prime \prime}$. The paddle was designed for trenslatory and rotary movement, and was driven by a constant speed motor, with fixed ratio reduction gears. The bed of the tank was concrete. The beach end was fitted with an adjustable bed plate to provide an inclined base for the beach material. The operational water depth was six inches.

Wave height and phase measurement were made by means of capacitance wire probes and long-after-glow oscilloscope. Details of breaking waves and run-up were obtained by cine photography.

\section{BEACH MATERIAL.}

For true similarity beach material should be moved by waves or currents at the corresponding depth, behave in a similar way in suspension, and be deposited in the correct relative position. In addition the rugosity and permeability of the material should correspond to the prototype values.

For the same specific gravity, fall velocity and permeability are similar functions of grain diameter. Absolute values depend on the coefficient of drag which in turn depends on the flow condition relative to the particle. This may be laninar, transitional or turbulent. If particles are sceled down they may be transferred from say turbulent prototype conaitions to transitional or laminar flow conditions in the model. The general hydraulic environment of the particle is also important. Here distinction must be made between conditions seaward of the breakers, and those landward of the breakers. The flow conditions in the seaward zone are likely to be very different in prototype and model. In and shoreward of the breakers fully turbulent conditions exist in both model and prototype, and dynamical similarity is good.

It may be concluded that a beach material chosen to represent conditions shoreward of the breakers, may not show results which are representative in the off'shore zone.

In the present instance the materials employed were chosen so that their fali velocities were outside the laminar range, with median diameters between $0.45 \mathrm{~mm}$ and $2.0 \mathrm{~mm}$. Both quartz sand and purnice were used, The present paper relates only to the quartz sand experiments, except where otherwise stated. 

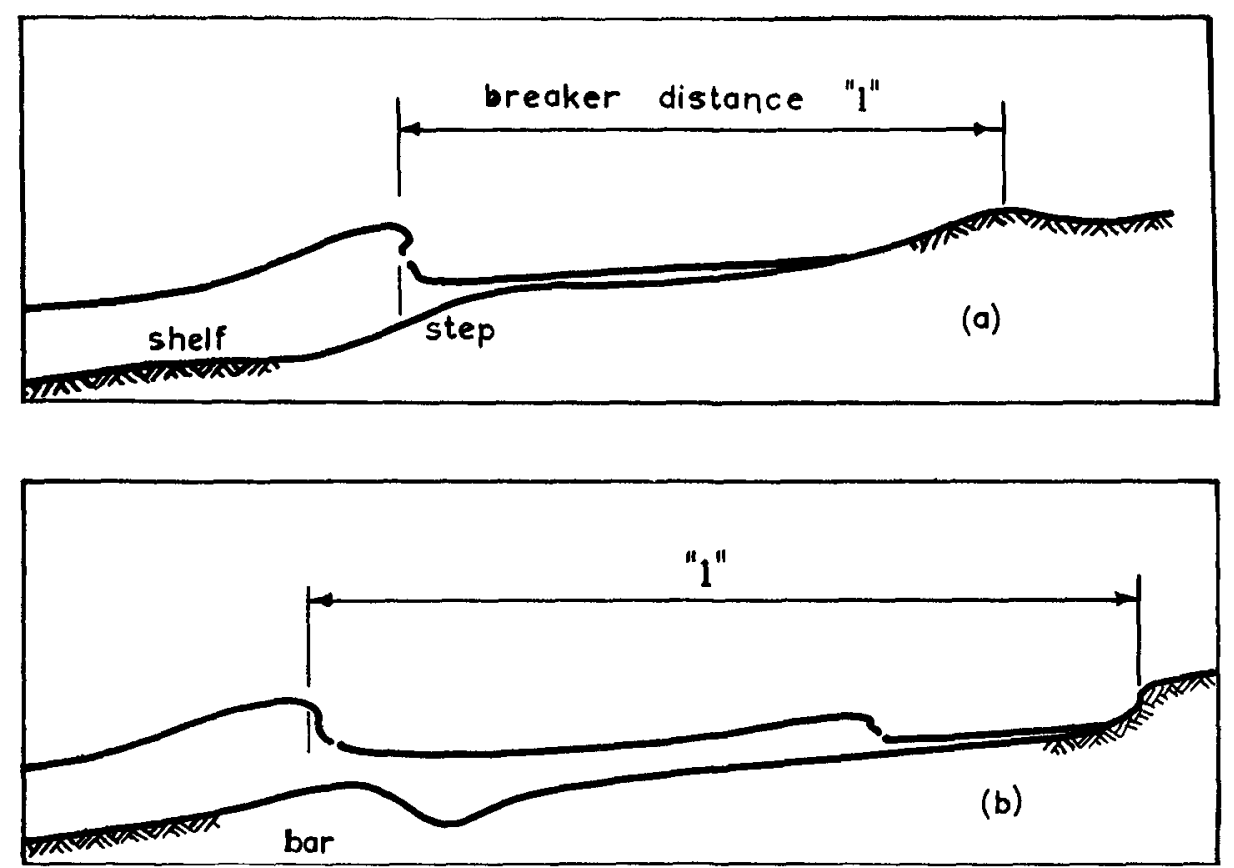

Fig. 1. Schematic step and bar type profiles.

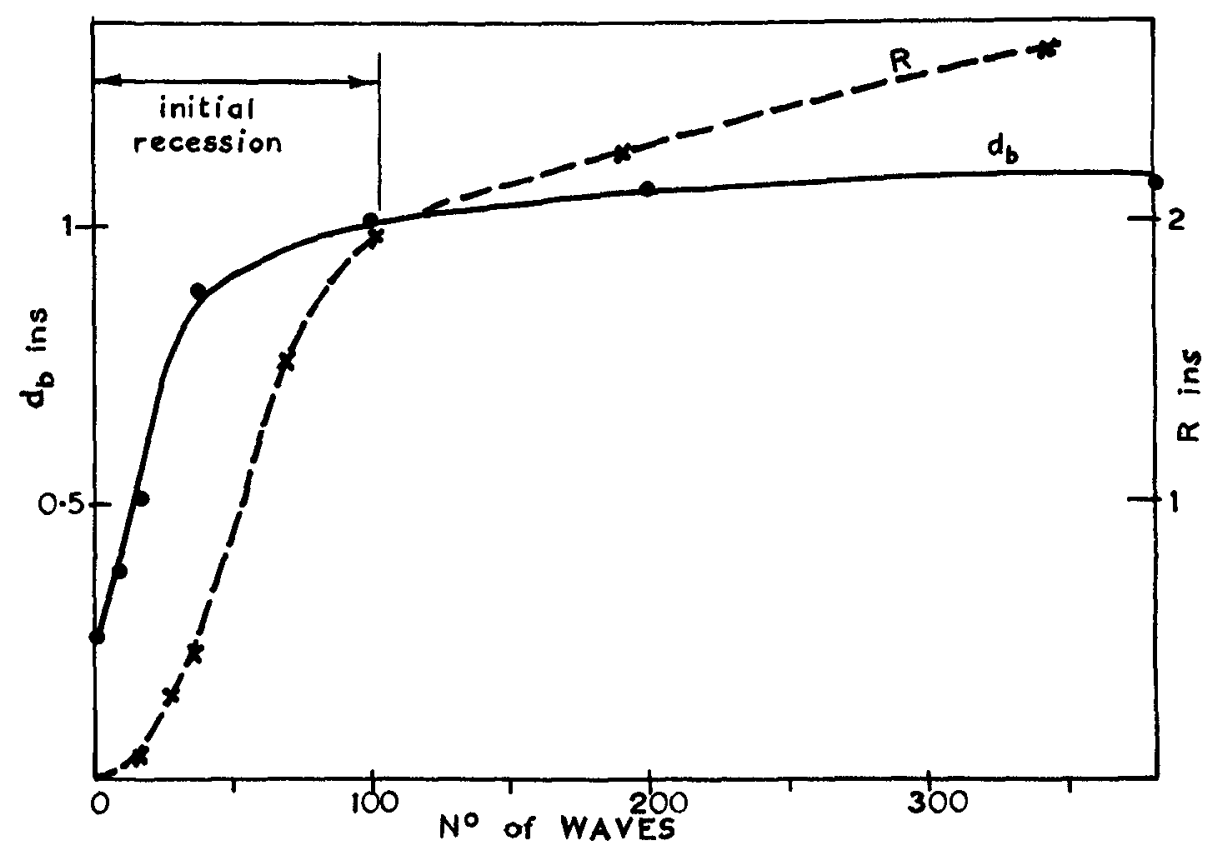

Fig. 2. Rate of shoreline recession $R$ and increase in breaker depth $d_{b}$ under severe wave attack. 
BXFERIMPNI : RA'TE OF BDACH ADJUSTMENT.

The rate at which a beach adjusts its profile to the onset of new and more severe wave conditions was first studied.

Having preformed the beach to a step profile using waves of period $\mathrm{T}=0.55$ secs, $\mathrm{H}_{\mathrm{O}}=0.48$ inches, the beach was attacked by waves of period $T=0.42$ secs, $H_{O}=1.17$ inches. The beach material in this experiment was pumice, median dia $0.9 \mathrm{~mm}$, specific gravity 2.0 , and fall velocity $4.1 \mathrm{~cm} /$ sec. Beach profile measurements were made after the following numbers of waves:-

$10,20,40,70,100,200,400$, and thereafter at 4 minutes, 9 mins, 13 mins and 25 mins, measured froin the beginning of wave attack.

The initial stages of beach adjustment are represented in Figure 2, where the rate of recession of the shoreline and the lowering of the beach step are plotted. The initial rate of recession is small until the original step has been destroyed.

Following this initial recession it was found that the rate of retreat of the shoreline was proportional to the logarithm of the time measured from the beginning of weve attack.

The most spectacular beach changes under storm conditions can therefore be observed in the early stages.

EXFURIMENT : PROFILE FORIATION, AID TRAISITION FROM STEP TO BAR PROFIIE

General Description. With low waves a step profile is formed. The step is created by a vortex produced by the backwash. The water flowing dow the beach in the backwash has a velocity distribution with a meximum in the upper lajers and a minimurn at the bed. On approaching the still water level the water is decelerated. The deceleration is usually accentuated by a rise in water level due to the proximity of the next wave crest. This deceleration results in the formetion of a vortex with a horizontal axis, in which the upper layers rotate downwards towards the bed and thence in a shoreward direction. Figure 3. The high velocities associated with this motion produce a scour depression. Some of the scoured material goes into suspension. The heavier particles are moved landward by the component close to the bed.

As the crest of the next wave reaches the break-point the high velocity of the horizontal component of its orbital motion near the bed produces a reverse vortex at the edge of the scour depression. Figure 3. This deepens the scour hole. At the sime time the orbital velocity "planes" the bed dowm in the area just seaward of the breakpoint, leaving a horizontal shelf. Some of this material is carried forward with the onwash to form the beach crest. 
THE RELATIONSHIP BETWEEN WAVE ACTION AND

BEACH PROFILE CHARACTERISTICS

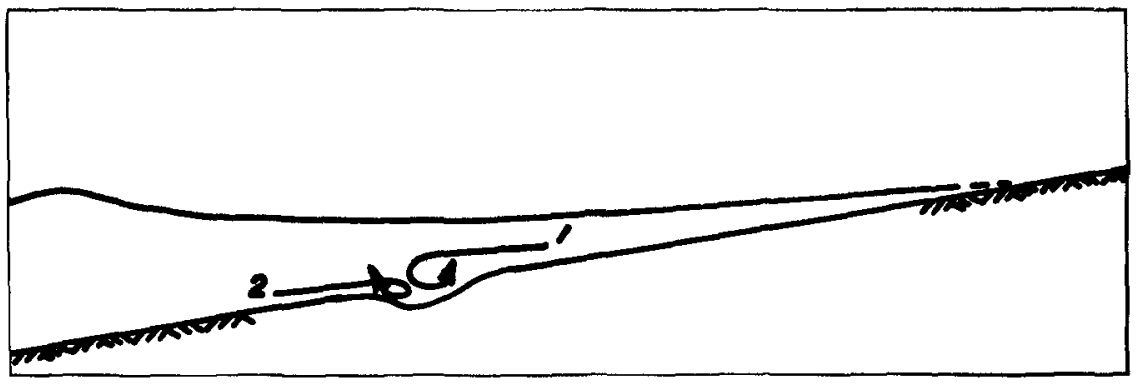

Fig. 3. Mechanism of step formation.

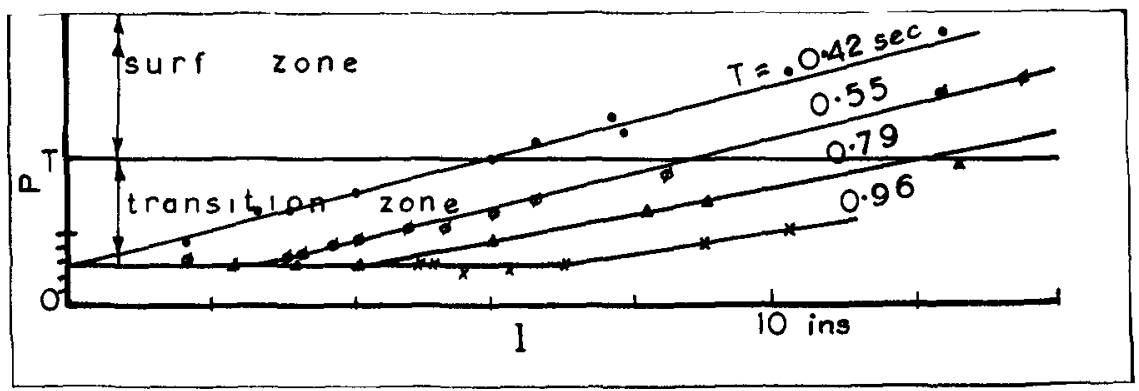

Fig. 4. Phase difference $P$ versus breaker distance 1.

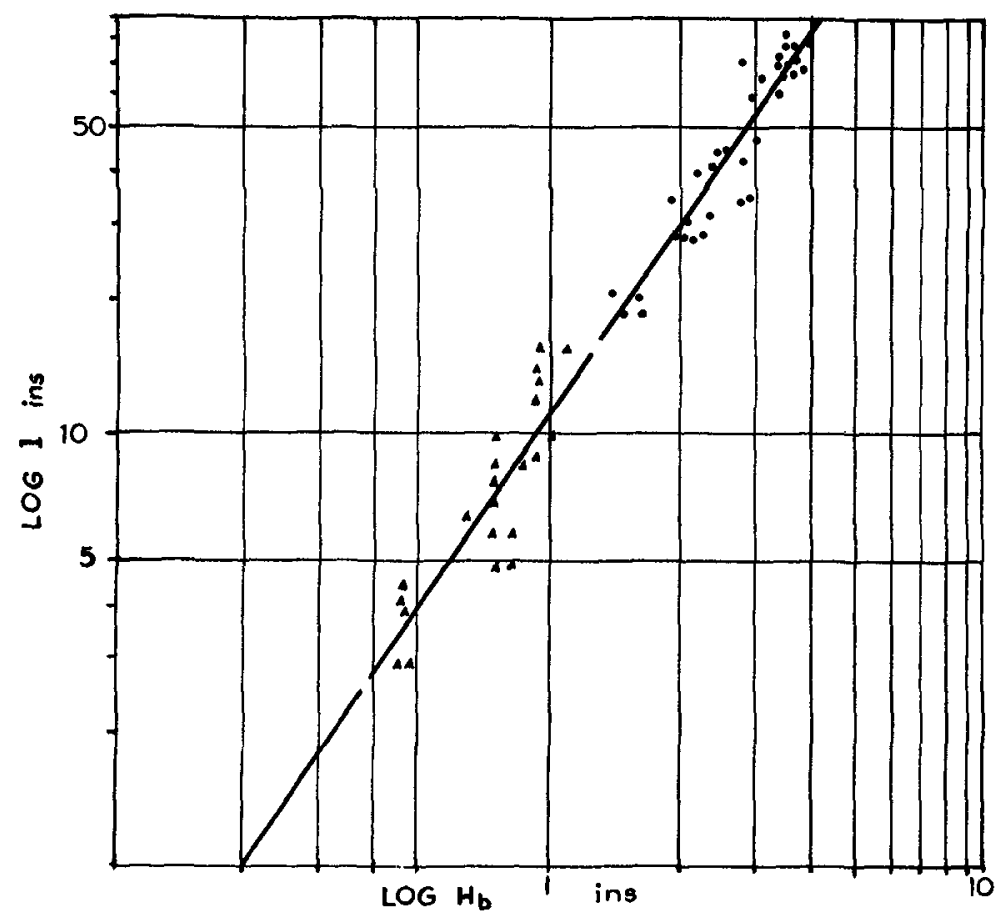

Fig. 5. Relationship between breaker distance and breaker height in the transition and surf conditions for several quartz sands. 
With increase in wave height the step moves seaward and the crest moves landward, the crest height initially increasing. With successive wave height increments the crest first reaches a maximum height, then decreases, and is finally flattened by the highest waves. The step profile gradually elongates. Material from the foreshore moves seaward to the break-point. Here the fine material goes into suspension and moves seaward through the breakers. The coarsest material is trapped at the bed on the seaward face of the step, building it seaward.

During this transition from step to bar profile, a scour hole or plunge pocket may form landward of the break-point, due to the turbulence created by the breaking wave assisted by the interference of the seaward flowing current of the backwash in the lower layers.

The step profile gradually becomes indefinite and finally changes to a bar profile.

After the bar profile has fully formed the breakers become less violent, since the momentum effect of the backwash is reduced. This is explained by the character of the return flow referred to under the heading "The Surf Condition " below. The plunge pocket may partly fill in.

Detailed Examination. In these experiments each wave period was held constant while a series of runs was made using different wave heights, starting with low waves and increasing the wave height for each run. The following observations were made:-

(1) wave height

(2) distance from break-point to limit of uprush, referred to below as the "breaker distance"

(3) time for the wave to travel from the break-point to the limit of uprush

(4) type of flow in the zone shoreward of the breakers

(5) regularity of the shoreline in plan.

If the time of uprush mentioned in (3) above is expressed in terms of the wave period, then it can be described as the " phasedifference" between break-point and beach crest.

The phase-difference was found to be the dominant factor in the relationship between the waves and the beach profile, and resulted in the following classification of wave/beach conditions.

The Surge Condition. Figure 4 shows phase-difference plotted against breaker distance for varying periods and wave heights.

Increase in wave height produces an increase in the breaker distance. Figure 4 shows that initially the phase difference or time of uprush remains constant at a value of approximately $0.3 \mathrm{~T}$, even though the breaker distance increases. The beach material in this instance was punice $0.9 \mathrm{~mm}$ median diameter. 


\section{THE RELATIONSHIP BETWEEN WAVE ACTION AND BEACH PROFILE CHARACTERISTICS}

As the breaker distance is further increased a critical point is reached at which the phase-difference ceases to be constant. Thereafter the phase-difference increases with increase in wave height.

The behaviour of the wave and the beach profile in the initial zone of constant phasemdifference resembles the behaviour of a simple pendulum. An increase in amplitude of the incident wave produces an increase in the velocity of the wave surge. The beach crest retreats and steepens but the time of the surge remains constant. This condition will be referred to as the "Surge Condition".

Flow conditions in the surge zone of behaviour are of the type noted by Begnold (7) in which negligible mixing or interchange takes place between the water seaward of the break-point and the shoreline. The motion is characteristically oscillatory.

It was observed in the case of all wave periods, that beaches formed under surge conditions were well sculptured and perfectly regular along the line of the beach. There wes no tendency for lateral circulation to take place.

The Transition Condition. With further increase in wave height a. point is eventually reached at which the beach crest to breaker distance ratio no longer satisfies the surge condition. This is the critical point already referred to. The crest hoight ceases to increase and later begins to diminish. With the retreat of the beach crest and the seaward movement of the break-point, the time taken for the wave to reach the crest increases. The time available for backwash before the next wave breaks is consequently reduced. As a result the backwash is not completed before the next wave plunges. This is the point of demarcation between the surge zone, with its stable oscillatory flow conditions, and the "transition zone" of behaviour characterised by unstable flow and lateral circulation.

The instability of the flow pattern under transition conditions inevitably results in locel lateral circulations being set up which enable the lack coincidence between the completion of the backwash and the next plunge, to be replaced by a continuous and self perpetuating pattern of flow between the break-point and the shore. This horizontal flow pattern is the origin of Beach Cusps.

Further observations on beach cusps were made which are outside the scope of the present paper. It will however be readily appreciated that if the waves are breasing obliquely to the shore, the littoral current forms an elternative or additional flow route for the backwash, and the development of cusps is retarded or eliminated according to the degree of phase-difierence in relation to the obliquity of the breakers.

Transition conditions are characterised by some interchange between the water in the zone seaward of the breakers and the nearshore zone. 


\section{COASTAL ENGINEERING}

The Surf Condition. As the phase-difference increases, the partly oscillatory nature of the onwash and backwash with limited interchange of water through the breakers gradually gives way to continuous flow into and out of the breaker zone. Continuous flow conditions become fully developed when the phase-difference becomes equal to the wave period.

This is the point at which the bar type profile achieves full development.

The flow conditions for phase-differences greater than the wave period $T$ will be calssified as the "surf condition".

The change from step to bar type profile is therefore a function of phase-difference. Hitherto the criterion has been that of critical wave steepness. However the variation in value quoted by different investigators is well known, and evidence that the value varies with beach slope (10) supports the phase-difference criterion.

Beach cusps disappear once surf conditions are established.

DOMINANT FACTORS RILATIMG BEACH AND WAVE CHARACTERISTICS.

This is in the nature of an interim report on the aspect of the investigation directed towards the determination of specific relationships enabling the results of model experiments to be applied to beaches in nature.

The model laws relating to gravity waves alone are well established. The difficulty arises in relation to the behaviour of the beach material under wave action.

One encouraging aspect of this problem is the observed fact that nodel beach profiles posess the general characteristics of their natural counterparts. A second point, alrerdy mentioned, is that the conditions for dynamical similarity are most likely to be found in the turbulent profile-forming zone between the break-point and the limit of the onwash.

It is clear that any scale reletionship of this type must reconcile two generally acicnowledged discrepancies between the model and nature, namely

(i) that the critical wave steepness values found in models for the change from step to bar type profiles are much higher than in nature

(ii) that model beach slopes are usually much steeper than in the prototype.

Ghoice of parameters. A number of investigators have nade dimensional analyses of the problem. The number of variables included 


\section{THE RELATIONSHIP BETWEEN WAVE ACTION AND BEACH PROFILE CHARACTERISTICS}

has been large, and as a result a correspondingly large number of non-dimensional groups have been derived. By keeping the number of variables to a minimum experimental verification is facilitated. The minimum choice must include (i) a wave characteristic (ii) a beach characteristic (iii) a beach material characteristic.

(i) The wave characteristic was chosen after making a limited but detailed study of the brearing wave under surf conditions. This confirmed that at and subsequent to the break the wave velocity corresponds very closely to that given by the solitary wave theory. In addition these experiments indicated that the envelope of wave height between the break-point and the limit of the onwash, shows an approximately linear decrease with distance.

The wave height at the break-point was therefore selected as the wave characteristic. The wave height adequately describes the solitary wave, since the water depth at the break-point is directly proportional to the wave height. The effect of shoaling on the wave length, wave celerity and height of oscillatory waves is thus eliminated.

(ii) The beach profile characteristic normally chosen is the beach slope. However, the slope of a beach is different at different points between the offshore zone and the shoreline, and both the choice of reference position and the accurate measurement of the slope in a smell model is not easy. On the other hand the engineer is primerily concerned with the determination of the landward limit of wave action under given conditions. In the present case therefore the variable chosen was the breaker distance. This in addition provided a link with the phese-difference experiments. Since the bed level at the break-point is related to the breaker height, an indirect measure of beach slope can be derived.

(iii) Both fall velocity and permeability are functions of grain diameter. Crain diameter is also a messure of roughness. To allow for the choice of materials posessing different specific gravities, both fall velocity and grain diameter were chosen as veriables.

\section{Using the following notation:-}

$$
\begin{aligned}
& \mathrm{H}_{\mathrm{b}}=\text { breaker height } \\
& \mathrm{I}=\text { breaker distance (from break to limit of uprush) } \\
& \mathrm{W}=\text { fall velocity } \\
& \mathrm{D}=\text { grain diameter } \\
& \mathrm{g}=\text { force per unit mass due to gravity }
\end{aligned}
$$

and with constant fluid characteristics, dimensional analysis leads to :-

$$
I=\mathrm{H}_{\mathrm{b}} \cdot \varnothing\left\{\left(\frac{\mathrm{g}^{\frac{1}{2}} \mathrm{H}_{\mathrm{b}}^{\frac{1}{2}}}{\mathrm{w}}\right),\left(\frac{\mathrm{H}_{\mathrm{b}}}{\mathrm{D}}\right)\right\} \ldots \ldots
$$

$$
\text { or } I=\mathrm{H}_{\mathrm{b}} \phi\left\{\left(\mathrm{N}_{\mathrm{F}}\right)^{\frac{1}{2}},\left(\frac{\mathrm{H}_{\mathrm{b}}}{\mathrm{D}}\right)\right\}
$$




\section{COASTAL ENGINEERING}

where $N_{F}$ is the Froude Number relating the wave and grain characteristics.

A series of preliminary experiments was undertaken to explore this relationship. Figure 5 shows a logarithmic plot of $I \vec{V} \mathrm{H}_{\mathrm{b}}$ for quertz sands ranging from 0.5 to $2.0 \mathrm{~mm}$ median diameter. The upper part of the curve consists of measurements computed from data published by Waters (3). The range of wave periods employed varled from 0.44 to 1.40 seconds. The effect of variation in grain diameter is not shown. The curve does not apply to the surge zone.

The curve indicates that for a constant specific gravity of grain of 2.64 and using coarse sands, the breaker distance 1 is proportional to $\mathrm{H}_{\mathrm{b}}\left(\mathrm{H}_{\mathrm{b}}\right)^{n}$ where $\mathrm{n}$ is approximately 0.5 .

$$
\text { i.e. } 1 \propto \mathrm{H}^{n+1}
$$

Segregation of data based on grain diameter so far carried out indicates that 1 is in fact also a function of $D$, and that the relationship can be written

$$
1=K \cdot H_{b}\left(\frac{H_{b}}{D}\right)^{n}
$$

Although sufficient data are not yet available to enable final values of $K$ and $n$ to be established, the value of $n$ seems to lie between 0.45 and 0.65 , and the approximate value of $\mathrm{K}$ is 24 when $\mathrm{H}_{b}$ is in feet units, and $\mathrm{D}$ is in m.m.

Provisionally therefore

$$
1=24 \mathrm{Hb}\left(\frac{\mathrm{Hb}}{\mathrm{D}}\right)^{0.5}
$$

The beach slope can be represented by the ratio $\frac{1}{\mathrm{H}_{\mathrm{b}}}$

since the breaker depth $\mathrm{db}$ is proportional to $\mathrm{Hb}$. Thus if $x$ is an horizontal coordinate, the cotangent of the beach slope becomes:-

$$
x \propto\left(\frac{H_{0}}{D}\right)^{n}
$$

Hence for the same grain dirmeter and specific gravity in model and prototype, the beach gradient scale distortion is proportional to the $n$th power of the vertical scale in the model. This assunes that the waves are produced to the vertical scale. For example, with a vertical scale of $1 / 40$, and $n=0.5$, the model beach slope would have a distortion of 6.3 .

$$
\text { In the surge zone, } \quad 1 \propto \mathrm{H}^{n} \text {. }
$$




\section{THE RELATIONSHIP BETWEEN WAVE ACTION AND BEACH PROFILE CHARACTERISTICS}

APPLICATION TO THE CHANGE FROM STEP TO BAR TYPE PROFILES.

As already shown the change from step to bar type profiles depends on the phase-difference. This in turn is a function of wave period and wave height for a given grain diameter. The beach slope is similarly a function of wave height and grain diameter. It is possible therefore to relate the change from step to bar profile to these chrracteristics.

The phase-difference involves the time $t$ for the wave to travel from the break-point to the limit of the onwash. Since the envelope of wave height decreases almost linearly with distance $x$ from the break-point, then the wave height dimension $h$ measured above the S.W.L. at any point distant $x$ from the breakers is given by

$$
h_{\mathrm{x}}=h_{b}\left(1-\frac{x}{1}\right)
$$

The celerity of the solitery wave is given by:-

$$
c=\sqrt{g\left(d_{b}+h\right)}
$$

Since both $d_{b}$ and $h_{b}$ are proportional to $H_{b}$, then

$$
\mathrm{c}=\sqrt{\mathrm{kg} \mathrm{H}}
$$

Introducing equation (6)

$$
c_{x}=\sqrt{k g H_{b}\left(1-\frac{x}{1}\right)}
$$

The time for the wave to travel an elemental distance $d x$ is $d t=\frac{d x}{C_{x}}$

$$
\text { whence } t_{x}=\int_{0}^{x} \frac{d x}{c_{x}}
$$

The total time $t$ for the wave to travel from the break-puint to the limit of the onwash is thus:-

$$
\begin{aligned}
t & =\frac{-2 I}{\left(k g H_{b}\right)^{\frac{1}{2}}}\left[\left(1-\frac{x}{1}\right)^{\frac{1}{2}}\right]_{0}^{I} \\
\text { i.e. } t & \left.=\frac{2 I}{\left(k g H_{b}\right.}\right)^{\frac{1}{2}}
\end{aligned}
$$

Since the full change over from step to bar profile occurs when the time of uprush equals the wave period $T$, then for a given period the critical condition is given by :-

$$
T=\frac{21}{\left(k g H_{b}\right)^{\frac{1}{2}}}
$$


If the depth at which the wave breaks $d_{b}$ is equal to $1.3 \mathrm{Hb}$, and the wave height asymetry $h=0.7 \mathrm{Hb}$ then

$$
T=\frac{21}{(2 \mathrm{~g} \mathrm{Hb})^{0.5}}
$$

For a given grain diameter $\quad 1 \propto\left(\mathrm{H}_{\mathrm{b}}\right)^{n+1}$

$$
\text { therefore } T \propto\left(\mathrm{H}_{\mathrm{b}}\right)^{n+0.0}
$$

If $\mathrm{n}$ is taken as 0.5 , the critical breaker height then varies directly with the wave period

$$
\begin{aligned}
\mathrm{H}_{b} \propto \mathrm{T} & \ldots \ldots(15) \\
\text { or } \mathrm{H}_{\mathrm{b}} \propto\left(\mathrm{I}_{0}\right)^{0.5} & \ldots \ldots(16)
\end{aligned}
$$

Comparison can now be made with the wave steepness criterion, since

$$
\frac{H_{b}}{I_{0}} \propto \frac{\left(I_{0}\right)^{0.5}}{I_{0}} \propto \frac{1}{T}
$$

In other words, the critical value of wave steepness varies inversely with the wave period.

For example, with a given beach material with a critical wave steepness value $\mathrm{Hb} / I_{0}$ of say 0.032 for $T=I$ second, the corresponding steepness value in nature for $T=8$ seconds would be equal to 0.004 .

By assigning specific values to $K$ and $n$ in equation (3) and to $k$ in equation (12), calculated values of breaker distance, critical wave height, and beach slope can be easily derived.

\section{DISCUSSION}

The paper hes attempted to present an integrated picture of the relationship between waves and beaches. Work is still proceeding, and where numerical values are given in the text, these must be regarded as provisional. It is never-the-less hoped that their presentation will lead to more specific evaluation.

In attempting to relate and apply the parameters to beaches of fine sand, it is possible the.t the immobility of such beaches under the action of small waves, may obscure the wave/beach profile relationship. In models, fine sand beaches not formed initially to the correct equilibrium slope, may be only pertially adjusted by subsequent wave action. Similar beaches in nature may develop a profile characteristic of a dominant wave, with only significant movement in the breaker area. Similarly on shingle beaches, if the waves are 


\section{THE RELATIONSHIP BETWEEN WAVE ACTION AND BEACH PROFILE CHARACTERISTICS}

relatively small compared with the size of the beach material, the beach may behave as a permeable wave absorber.

For wave periods less than 2 seconds, Diephuis (11) has show that the wave steepness becomes a differential frator in reletion to the breaker depth. This could affect the breaker distance es computed from the breaker height. In the present experiments the exclusion of wa ves with high initial steepness ond of short period from the results did not affect the wave/breaker distance relationship.

\section{SUMDARY.}

1. The turbulent conditions in and shoreward of the breakers in both model and prototype are conducive to dynemic similarity.

2. The rate of berch adjustment under more intense wave action is initielly high, but decreases logorithmically with time.

3. The phase-difference or ratio between run-up time and wave period, is the dominant factor in determining the characteristic shape of the beech profile. The phase-difference criterion enables wave conditions to be classified as 'surge', 'transition', or 'surf', each with characteristic flow patterns.

4. The transition from step to ber type profile is fully achieved once surf conditions are established.

5. Beach cusps ore initiated and developed by the three dimensional flow pattern which occurs when the phesedifference ratio is in the unstable trensition zone. Cusps do not occur under surge or surf conditions.

6. The dominent factors for dimensional similarity in relation to beach profiles, are :-

(a) breaker height ( $\mathrm{H}_{\mathrm{b}}$ )

(b) breaker distance (1), i.e. the distance from

(c) the break-point to the limit of the onwash
(c) fall velocity of the grein (w), and the grain diameter (D).

7. For beach materials of a given specific gravity, the relationship between the beach profile dimensions and the wave characteristics is of the form below for transition and surf conditions

$$
I=K H_{b}\left(\frac{H_{b}}{D}\right)^{n}
$$

(For surge conditions $1 \propto\left(\mathrm{H}_{b}\right)^{n}$ ). 


\section{COASTAL ENGINEERING}

8. The cotangent of the beach slope is proportional to $(\mathrm{H} / \mathrm{D})^{\mathrm{n}}$. Model beach slope distortion is thus proportional to the $n$th power of the vertical scale.

9. The numerical value of the power $n$ referred to in paragraphs 7 and 8 above, is of the order of 0.5 . The scatter of values so far obtained lies between 0.45 and 0.65 .

10. The critical wave height at breaking for the transition from step to bar type profile is a function of the wave period $T$, viz

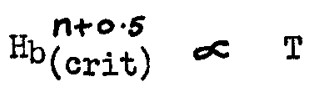

which for a value of $\mathrm{n}=0.5$ becomes $\mathrm{Hb}$ (crit) $\propto \mathrm{T}$

11. Values of breaker distance, critical wave height, and beach slope, can be readily dexived from the relationships developed above.

\section{REFERENGES.}

Kemp, P.H. The effect of groynes on beach formation and erosion. $\mathrm{Ph}, \mathrm{D}$ Thesis. University of Iondon. 1958.

1. Cornish Vaughan. On sea beaches and sandbanks. Geog. Jour. 11 1898, pp. 528-543, 628-651.

2. Fenneman, N.M. Developnent of the profile of equilibrium of the sub-aqueous shore terrace. Jour. Geol., 10, 1902, pp. 1 - 32 .

3. Waters, C. H. Equilibrium slopes of sea beaches. Thesis. University of California, 1939.

4. Patrick D.A. \& Wiegel R.I. Amphibian tractors in the surf. Ist Confee on Ships and Waves. 1955. Ch. 29.

5. Beach Erosion Board. Coast erosion and the development of beach profiles. Tech. Memo. 44, Corps of Engrs. U.S.A. 1954.

6. King, C.A.M. The relationship between wave incidence, wind direction and beach changes at Narsden Bay, Co. Durham. Inst. Brit. Geog. Trans. 1953. Pubn 19.

7. Bagnold, R.t. Beach formation by waves. Some model experiments in a wave tank. Jour.I.C.E., 15,1940 - 4l. p. 38 . 


\section{THE RELATIONSHIP BETWEEN WAVE ACTION AND BEACH PROFILE CHARACTERISTICS}

8. Beach Erosion Board. Laboratory study of effect of tidel action on wave-formed beach profiles. Tech. Memo. 52, Corps of Engrs U.S.A., 1954 .

9. Beach Brosion Board. Laboratory study of the effect of varying wave periods on beach profiles. Tech. Memo 53, Corps of Engrs, U.S.A., 1954.

10. King, C.A.H. Beaches and Coasts. Arnold, London. 1959. p.184.

11. Diephuis, J.G.H.R. Scale effects involving the breaking of waves. Proc. 6th Confce Coastal Eng. 1957, p. 199. 